\title{
Effect of the physical and mechanical properties of composites on their grinding characteristics
}

\author{
S. D. El Wakil \& K. Srinagesh \\ Department of Mechanical Engineering, \\ University of Massachusetts Dartmouth, USA
}

\begin{abstract}
Experiments were carried out on different fiber-reinforced polymeric composites in order to gain a deeper understanding of the significance and effect of each of the physical and mechanical properties of the various composites on the quality of the machined surface during cylindrical grinding. For such a comparison to be valid the process parameters such as feed rate, depth of cut, and R.P.M. were kept constant in each case. The results enabled understanding of the phenomena of heat generation and heat dissipation during the grinding process. They would also serve as an aid in selecting the appropriate type of composite for a specific application.
\end{abstract}

Keywords: fiber-reinforced polymeric composites, grinding, properties of composites.

\section{Introduction}

While fiber-reinforced polymeric composites are currently very popular in fabricating boats, skiing gear, automobile panels, small rockets, and aircrafts, their use as structural machine components has been quite limited. This is mainly due to the difficulties encountered in achieving adequate levels of dimensional accuracy and surface finish when those composites are subjected to precision machining operations, e.g., grinding. Problems such as degradation, thermal damage of the ground surface, excessive noise and vibrations, and clogging of the grinding wheel are frequently encountered. This is evidently caused by the nature and the physical and mechanical properties of this class of material, which are different from those of metals. 
The present work constitutes a part of a long-term investigation into the grinding of FRP composites, carried out at the University of Massachusetts Dartmouth, in which the current paper is a continuation of and is based on previous work by Laoulache and El Wakil [1] and Fares [2]. It enabled giving a deeper insight into the effects of the physical and mechanical properties of the composites on their grinding characteristics.

\section{Analysis of the problem and approach}

Detailed analysis of the process of cylindrical grinding of fiber-reinforced polymeric composites has been covered in earlier published work [1,2]. It is based on observations and explanations provided by earlier researchers [3-6]. It is well-established that when machining any material, heat is generated and is then dissipated into the surroundings, i.e., the work piece materials and the cutting tool. But, since the thermal conductivity of composites is much poorer than that of metals, heat is not transferred easily and quickly from the area being machined, and would therefore result in a localized increase in the temperature of the surface of the work piece being machined, as reported by Lee and Kim [7]. Now, bearing in mind that the coefficient of thermal expansion for polymers is almost ten folds than that for metals, the radial expansion of the composite work piece would be significant compared to that of a metal work piece. The final outcome can be thermal damage of the surface of the composite work piece, excessive noise and vibrations, poor surface quality, and even clogging of the grinding wheel.

It is evident from the above-mentioned analysis that - for the same grinding wheel - the physical and mechanical properties of the work piece, as well as the grinding process variables would have a noticeable effect on the grinding operation and on the quality of the machined surface. Therefore, grinding experiments had to be designed, with their response later subjected to the appropriate treatment for analysis and interpretation. Evidently, it is not difficult to identify the fiber-to-epoxy ratio as our prime factor since it significantly affects the physical and mechanical properties of the composite, which-in-turnaffect the grinding operation and the quality of the machined surface.

\section{Equipment, materials, and experimental procedure}

Throughout the experimental work, graphite-epoxy tubes each was about $0.15 \mathrm{~m}$ in length, $0.1 \mathrm{~m}$ in diameter, and $0.05 \mathrm{in}$. in thickness, were used. The fiber-toepoxy ratio by volume varied and took the values of 70 to 30,50 to 50 , and 0 to 100 (i.e., pure epoxy). The fibers of the outer layers made an angle of 80-110 degrees with the axis of the tube. Knowing the properties of the fibers and the epoxy, which were provided by the suppliers, the properties of the composites used could be determined by the rule of mixture, and are given in table 1 .

The cylindrical grinding was carried out on a precision GHB-1340 gear head lathe made by JET Equipment and Tools. The work piece (composite-tube) was firmly held by a split collect (made by Dunham Tool Company) which was in 
turn chucked. A grinding attachment, with the grinding wheel, was mounted on the carriage of the lathe. The attachment had its own electric motor and dial indicator was used to ensure that its axis was always parallel to the axis of the lathe. The work piece rotation was $70 \mathrm{R}$. P. M. and the axial feed was automatically provided by carriage, whereas, the depth of cut was controlled by the cross-slide. Based on our previous experience the type of grinding wheels used in this investigation was designated AZ46-I-8-V32A, according to the Standard Marking System. That wheel has coarse grains, but soft grade.

Table 1: $\quad$ Properties of the different work piece material.

\begin{tabular}{|l|r|r|r|}
\hline \multicolumn{1}{|c|}{ Fiber-to-epoxy ratio } & 0 to 100 & 50 to 50 & 70 to 30 \\
\hline Density $\mathrm{kg} / \mathrm{m}^{3}$ & 1200 & 1458 & 1633 \\
\hline $\begin{array}{l}\text { Specific heat } \\
\mathrm{J} / \mathrm{Kg} \cdot \mathrm{K}\end{array}$ & 1400 & 1070 & 938 \\
\hline $\begin{array}{l}\text { Coefficient of thermal } \\
\text { conductivity } \mathrm{W} / \mathrm{m} \cdot \mathrm{K}\end{array}$ & 0.21 & 3.6 .5 & 4.963 \\
\hline $\begin{array}{l}\text { Volumetric specific heat } \\
\mathrm{J} / \mathrm{m}^{3} \cdot \mathrm{K}\end{array}$ & $1.68 \times 10^{6}$ & $1.56 \times 10^{6}$ & $1.532 \times 10^{6}$ \\
\hline $\begin{array}{l}\text { Thermal diffusivity } \\
\text { (thermal } \\
\text { conductivity/volumetric } \\
\text { specific heat) } \mathrm{m}^{2} / \mathrm{sec}\end{array}$ & $0.125 \times 10^{-6}$ & $2.31 \times 10^{-6}$ & $3.24 \times 10^{-6}$ \\
\hline
\end{tabular}

Since the main objective of the current investigation was to study the effects of heat retention at the surface layer of the work piece, no coolant was used during the grinding operations. Throughout the experiments, the feed rate of the grinding wheel, as well as the depth of cut were determined. However, the temperature of the surface of the work piece and that of the grinding wheel could not be measured. After each grinding operation, the surface roughness of the work piece was measured by means of a surface roughness gauge, and its value was taken as a quantitative indication of the quality of the surface. Furthermore, in order to eliminate the drawbacks of using dull tools, the grinding wheels were frequently dressed throughout the experimental work.

\section{Experimental results and discussion}

The variables included in this set of experiments are the following:

1. Two composites with $50 \%$ and $70 \%$ graphite fiber in an epoxy polymer matrix, that were produced by filament winding in a cylindrical form, are machined by grinding. Another work piece made of the same polymer with 
no fiber, cast to the same size and shape as the test specimens was used as the reference.

2. Three different depths of cut, namely $0.25 \mathrm{~mm}, 0.50 \mathrm{~mm}$, and $0.76 \mathrm{~mm}$ were tried.

3. Two feed rates, namely 0.61 and $0.75 \mathrm{~mm} / \mathrm{sec}$ were tested with.

4. The tool for cutting the grinding wheel while cutting remained unchanged.

The criterion in this experiment was to obtain as smooth a machined surface as possible, corresponding to several combinations of the above parameters. The surface smoothness was measured in terms of "surface roughness," using an electronic surface roughness gauge. Following are the results given in tables 2 and 3 , and plotted in figures 1 and 2 .

Table 2: $\quad$ Surface roughness for different depths of cut at $0.74 \mathrm{~mm} / \mathrm{sec}$ feed rate.

\begin{tabular}{|l|l|l|l|}
\hline \multicolumn{1}{|c|}{ Depth of cut mm } & \multicolumn{3}{|c|}{ Surface roughness in micrometer } \\
\hline 0.254 & 1.16 & 1.93 & 1.98 \\
\hline 0.508 & 1.93 & 2.18 & 2.33 \\
\hline 0.762 & 1.05 & 2.33 & 1.87 \\
\hline
\end{tabular}

Table 3: $\quad$ Surface roughness for different depths of cut at $0.61 \mathrm{~mm} / \mathrm{sec}$ feed rate.

\begin{tabular}{|l|l|l|l|}
\hline \multicolumn{1}{|c|}{ Depth of cut $\mathrm{mm}$} & \multicolumn{3}{|c|}{ Surface roughness in micrometer } \\
\hline 0.254 & 1.29 & 1.81 & 1.93 \\
\hline 0.508 & 1.35 & 2.10 & 2.03 \\
\hline 0.762 & 1.39 & 2.93 & 1.88 \\
\hline
\end{tabular}

For the common background in this context, it has to be borne in mind that each curve indicating a certain depth of cut with a given feed rate is also indicating a corresponding fixed material removal rate (MRR), since the RPM of cutting - the relative motion between the cutting wheel and the work piece remains constant. But the rate of energy generated as a result of grinding, differs for different composites having different fiber content; the higher the fiber content, the higher the energy. This is so because the rate of energy generated is given by the product of MRR and the specific energy (the amount of energy needed to remove unit volume of material per second). Specific energy, in turn, is basically dependent upon the strength of the material and invariably, the strength of the composite is higher than the strength of the matrix alone - in this case an epoxy. Further, invariably, in a given fiber-matrix combination, the strength increases with increasing volume fraction of fiber. 


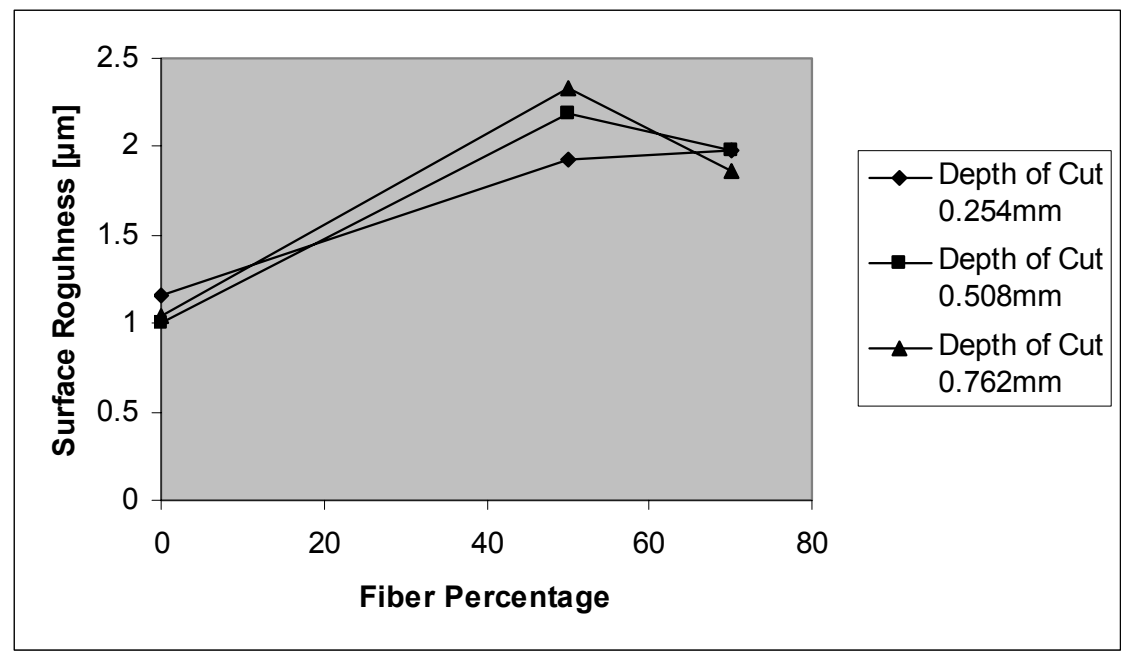

Figure 1: $\quad$ Effect of percentage fiber on surface roughness, feed rate 0.74 $\mathrm{mm} / \mathrm{sec}$.

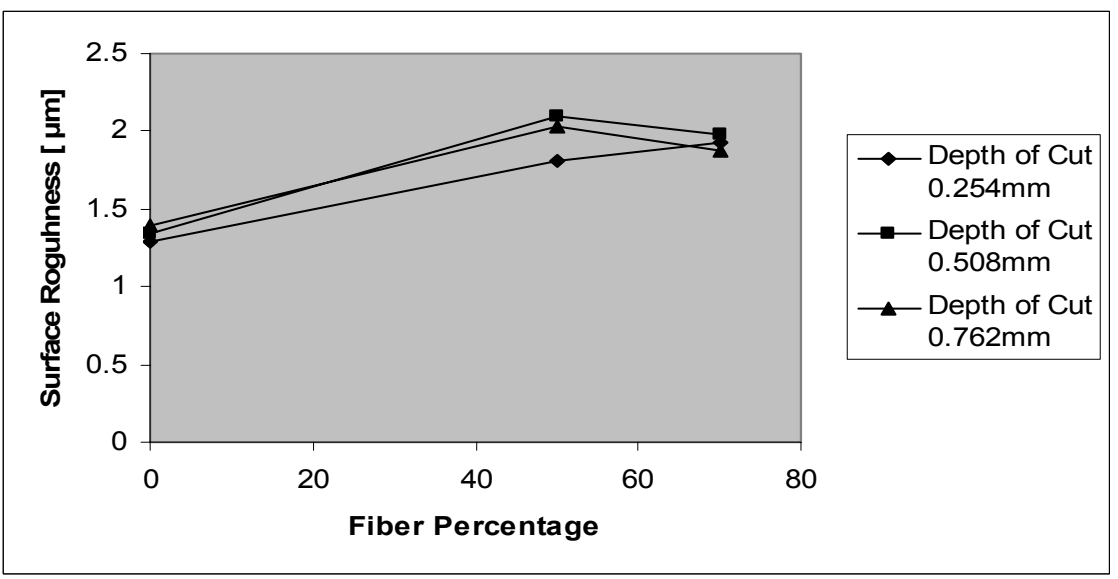

Figure 2: $\quad$ Effect of percentage fiber on surface roughness, feed rate 0.61 $\mathrm{mm} / \mathrm{sec}$.

Considering these well-known factors of composites, one should expect that a composite with higher fiber content, under otherwise identical conditions of machining, will generate higher quantity of heat. The heat generated, if not removed from the cutting spot, will char and then burn the matrix component. In our case, the polymer, an epoxy, being thermosetting, the matrix will directly char and burn out. The exposed fiber results in higher surface roughness.

This phenomenon, in machining of composites with polymer matrix, is often referred to as "thermal damage." This is what we observe reference to Fig. 1 and 
Fig. 2. With the fiber content increased from $0 \%$ to $50 \%$, there is an average increase in roughness from 1.38 to $2.15 \mathrm{~mm}$ in Fig. 1 and from 1.35 to 2.28 in Fig. 2.

But with fiber content increased from $50 \%$ to $70 \%$, in both Fig. 1 and Fig. 2, the above trend is not consistent. Instead, at the lowest depth of cut in both the figures, there is an increase in roughness as before, though less pronounced. For the two cases of higher depth of cut $(0.51$ and $0.76 \mathrm{~mm})$ in each figure, there is a decrease in roughness. And the decrease is more for the higher depth of cut $(0.76 \mathrm{~mm})$ than for the $(0.51 \mathrm{~mm})$. That is, with increasing heat generated better surfaces are obtained. This observation is in contradiction to what we mentioned above as "thermal damage."

To account for this anomaly, we turn to a property of the material known as thermal diffusivity, listed with other physical properties in Table 1 . We notice that only the numerical value of this property for epoxy is $0.125 \times 10^{-6}$. With $50 \%$ fiber it increased to 2.31 and with $70 \%$ fiber, it further increased to 3.24 . Comparing the property of the material with $0 \%$ fiber with the same property of the material with $50 \%$ fiber cannot be justified because these two materials are quite different in nature - are a pure polymer, and another a composite with $50 \%$ polymer, the other $50 \%$ being graphite fiber. On the other hand, comparing thermal diffusivity, of a composite with $50 \%$ fiber with the same property of a composite with $70 \%$ fiber is quite justifiable.

Now, we return to our observation that for machining condition involving higher heat generation, we obtained a smoother surface. There has to be more heat generated in cutting the material with higher fiber content. But owing to its higher diffusivity, out of the total quantity of heat generated, the fraction of that amount of heat carried away is much higher. The resulting temperature at the surface being cut is considerably lower. Surprising as it may seem the work piece, which while cutting generates more heat actually works with cooler surface.

\section{Conclusion}

In finish grinding cylindrical shaped composites made with epoxy matrix and graphite fiber, the following observations were made:

1) Composite with $50 \%$ fiber obtained rougher surface than epoxy alone ( $0 \%$ fiber).

2) Composite with $70 \%$ fiber obtained smoother surface than the composite with $50 \%$ fiber.

3) Though the composite with $70 \%$ fiber could have generated more heat in cutting than the one with $50 \%$ fiber, the former could have worked at lower temperature than the latter. This possibility could be attributed to the property, known as thermal diffusivity of the material.

4) Considering observation 2 above, when smooth surface finish grinding is a requirement, it is desirable to use composites with more than $50 \%$ fiber. 
5) Progressively smoother surfaces may be expected with percentage of fiber increasing beyond 60 .

6) To take advantage of the effect of thermal diffusivity of composites with high percentage of fiber, deeper cuts are preferable in conformity with other limitations.

\section{Acknowledgements}

This publication is sponsored by the US-Egypt Science and Technology Joint Fund Project, MAN8-001-003, through a National Science Foundation (NSF) grant, whose generous financial support is greatly appreciated. Some of the raw results were obtained by Mr. Raj Desai during his Masters work, and the authors would like to acknowledge his work.

\section{Reference}

[1] Laoulache, R. N., and El Wakil, S. D., "Grinding of fiber-reinforced Composites," Proceedings of the Sixth International Conference on Production Engineering \& Design for Development, pp. 134-142, 2002.

[2] Fares, G. F., "Grinding of Fiber-Reinforced Polymeric Composites," Masters Thesis, University of Massachusetts Dartmouth, 2006

[3] Snoeys, R., Lewen, K. U., Maris, M., and Peters, J., "Thermally induced damage in grinding," Annals of the CIRP, vol. 27, No. 2, pp. 571-581, 1978.

[4] Kim, J., and Lee, D. G., "Grinding Characteristics of carbon fiber epoxy composite hollow shafts," Journal of Composite Materials, vol. 34, No. 23, pp. 2016-2035, 2000.

[5] Park, K. Y., Lee, D. G., and Nakagawa, T., "Mirror surface grinding characteristics and mechanism of carbon fiber reinforced plastics," Journal of Materials Processing Technology, vol. 52, pp. 386-398, 1995.

[6] Eshghy, S., "Thermal aspects of the abrasive cut-off operation," Journal of Engineering for Industry, vol. 66, pp. 356-364, 1967.

[7] Lee, D. G., and Kim. P. J., "Temperature rise and surface roughness of carbon fiber epoxy composites during cut-off grinding," Journal of Composite Materials, vol. 34, No. 23, pp. 2061-2080, 2000. 